\title{
DEMOCRACIA Y ÉTICA: UNA ENTREVISTA CON FERNANDO SAVATER
}

\section{Dr. Bienvenido Argueta Hernández}

El 29 de octubre de 2003 el académico Fernando Savater ofreció una conferencia sobre "La ética de la desesperanza" para la entrega de los Premios a la Comunicación que organiza anualmente el Fondo de las Naciones Unidas para la Infancia -UNICEF-/Guatemala. Savater quién es uno de los filósofos y escritores más importantes en España, tiene una amplia publicación de obras relacionadas con la problemática de la ética, la política, las humanidades y la educación. Entre sus principales obras se encuentran las siguientes: Humanismo Impenitente (2000), Ética para Amador (2000), El Valor de Educar (2001), Política para Amador (2003), Mira por dónde (2003) y Los Caminos para la Libertad: Ética y Educación (2003), entre otros. Durante su estadía en Guatemala, el profesor Savater concedió la presente entrevista para discutir temas relacionados con la dinámica del debate teórico acerca de los procesos democráticos en América Latina y su incidencia en ámbitos como los de la Educación, particularmente en contextos socioculturales diversos. Como es característica de la personalidad del entrevistado siempre muestra un entusiasmo y una afirmación en las posibilidades del proceso de construcción de comunidades abiertas a la crítica y al debate de los problemas que hoy día aquejan al mundo.

B.A.: Siguiendo su desarrollo filosófico, se observa que uno de los temas que constantemente aborda es el de educación y el humanismo. En ese sentido, después de la segunda guerra mundial, los sistemas educativos de los distintos países toman el humanismo como uno de sus fundamentos. Sin embargo, años después vemos cómo está el mundo y todavía somos testigos de las atrocidades a pesar de ese pretendido humanismo. Usted insiste en el tema humanista, por ejemplo en sus libros el "Humanismo impenitente", en "El valor de educar" y otras obras. Sin embargo, también observamos que alrededor del mundo hay reformas educativas en las cuales el plano tecnocrático aborda la primera escena. ¿Cómo ve usted esta situación? ¿Cómo podríamos abordar el humanismo en educación ante estas situaciones que están ocurriendo? 
F.S.: Lo primero es que la principal función de la educación es humanista, en el sentido en que se dirige a formar seres humanos plenos, capaces de utilizar la acción democrática, capaces de potenciar una masa crítica y creadora de sus capacidades, es decir, no son simplemente personas con una destreza laboral determinada sino personas capaces de desarrollar su humanidad y de reconocerla y potenciarla en otros también. $Y$ esa es la función humanista de la educación. No se trata tanto que la educación deba abordar temas de los tradicionalmente considerados humanísticos, como el latín, el griego, las matemáticas. Yo creo que hay una forma humanista de abordar todos los temas y que lo importante es que esa sea la forma en que se aborden. Luego, no se trata tanto de que sea específicamente una u otra disciplina la que se dé. Es importante para las disciplinas que tratan de los fines y no de los medios, como lo es la filosofía o literatura, se potencien. No creo que debamos simplemente limitarnos a ellas. Creo que nuestro mundo exige para un buen desarrollo y el propio humanismo, un conocimiento de instrumentos, de mediaciones técnicas que son muy importantes y enriquecedoras.

B.A.: Claro, esto también tiene que ver con lo que constantemente se espera de las humanidades: la formación de lo público. En la actualidad también se observan dificultades en términos de lo que sería la constitución de esa esfera pública, que es factible a partir de las humanidades.

F.S.: No. Es factible a partir de las instituciones políticas, no de las humanidades que permiten desenvolvernos probablemente en algunos aspectos como la destreza para argumentar, para entender textos, para comprender argumentos ajenos, que todo esto es fundamental para las relaciones humanas. Una de las funciones de la educación es potenciar a crear caracteres capaces de persuadir y de ser persuadidos, y la esfera pública debe ser creada por las instituciones políticas, los medios de comunicación, etc. No es una esfera que dependa exclusivamente de la educación aunque ésta prepara para intervenir en esas esferas.

B.A.: En términos de lo público y las instituciones políticas también vemos una tendencia general a nivel de la filosofía, particularmente en Europa, de reflexionar sobre la problemática de como las dificultades de hacer y construir sociedad. Incluyendo posiciones que dejan de creer en metarelatos históricos y sociales. ¿cómo ve usted ese proceso de la formación de lo público? Y ¿cómo las instituciones políticas crean ese espacio? Si también 
se observa la crisis de legitimidad de los sistemas políticos y la creciente desesperanza por los procesos democráticos en Latinoamérica?

F.S.: Bueno, yo creo que en Latinoamérica hay una desesperanza porque no llegan los procesos democráticos o porque no son efectivamente democráticos los procesos. En Europa hay un cierto hastío (disgusto o tedio) porque la democracia es un instrumento que exige ser utilizada todos los días. No basta con instaurarlo y ya echarse a dormir, no es un piloto automático. Entonces la gente se cansa. Aquí en América más bien, hay el sueño de una verdadera democracia y la desesperanza viene de ver que hay dificultades culturales, militares. Y en Europa que sí existen las democracias pero que hay ese hastío de que ahora hay que trabajar por ellas iqué aburrimiento de estar todos los días practicándola! O sea, que en un caso se deplora la ausencia del instrumento y en otro, se deplora la presencia del instrumento que lo obliga a utilizarlo.

B.A.: En la actualidad usted forma parte de un debate por su posición con el movimiento etarra en España. La discusión tiene como trasfondo la polémica sobre la política y las diferencias culturales. En el caso de Guatemala se observa la emergencia del discurso reivindicativo de parte de los distintos grupos étnicos en Guatemala (Mayas, Garifunas y Xincas). Estos planteamientos a favor del reconocimiento de las diferencias demandan un replanteamiento de la teoría tradicional tanto en la filosofía como en la política y la sociología. ¿Cómo comprende la relación entre la política, las diferencias culturales y la democracia?

F.S.: Las diferencias culturales depende a qué nivel se instauren. En una democracia lo principal es compartir una cultura democrática, que debe ser imprescindible en una democracia. Todas las demás pueden ser enriquecedoras, pero son accesorias. En una democracia lo fundamental es que exista cultura democrática, es decir, que los principios de una democracia se hayan convertido en la verdadera base de los valores culturales de la mayoría de la población. A partir de allí, hay naturalmente diversos enfoques sobre todo cuando las sociedades, casi todas, son mestizas, de diversas procedencias étnicas, religiosas, lingüísticas, artísticas, y todo ello forma parte de una nueva apertura, que mientras no choque con la base común e imprescindible de la democracia, no son negativas sino positivas. El problema es cuando hay personas que se sienten dispensadas de la cultura democrática o quizá por grupos humanos que no han conocido más que los aspectos 
depredadores de la democracia. Naturalmente no se sentirán vinculados a unas instituciones que no les han ofrecido verdaderas garantías. Lo que falta es, primero una extensión auténtica de la ciudadanía a todos los participantes de la sociedad para que todos ellos de alguna manera se den cuenta de las posibilidades de una democracia y ajusten sus diferencias culturales a esa democracia compartida.

B.A.: Habermas nos señala que la constitución principal de la ciudadanía; también tiene que ver con toda la constitución del individuo. Las democracias europeas liberales se instauraron sobre la base de sociedades que reconocieron a los ciudadanos como individuos iguales frente a la ley. Aún para democracias deliberativas, es también complejo cuando los movimientos de distintos grupos indígenas de América Latina y alrededor del mundo resaltan el sentido de grupo frente a la noción de individuo. Aún los derechos humanos son vistos como parte de la lógica occidental, que somete y que no reconoce el derecho de los pueblos. Incluso llegan a contraponer los derechos humanos como derechos individuales frente a los derechos de los pueblos. ¿Cómo ve usted esta situación?

F.S.: Primero hay que aclarar que todos somos indígenas. No hay gente que no lo sea de una cultura, tradición, etc. Por lo tanto no hay nadie que pueda reclamar el indigenismo que está en el mundo. Lo que pasa es que hay indígenas que han seguido unos caminos y otros que han seguido otros y otros que no se han movido del primero. Pero eso no quita que todos seamos indígenas. Entonces hay que elegir entre cómo ser indígena. Mejor y naturalmente la democracia está basada en que son los ciudadanos los que centran la vida pública y no la sociedad, la sociedad es para los ciudadanos y no los ciudadanos para la sociedad. Por eso decía (usted), que eso es la base fundamental, es una lógica occidental, oriental y de todas partes donde hay democracia. Todo se codifica naturalmente en algún lugar. La democracia se codifica en Grecia, se traslada a Inglaterra y a Francia y después a estados unidos, etc. Y sigue una deriva que es la potenciación del individuo como centro de la sociedad y como liberador de toda sociedad y no como el acatamiento a aquellos elementos que uno no elige sino que recibe de la tradición. Esas tradiciones que ponían la religión y los pueblos, han existido en todas partes. Es decir, no es que sean orientales $u$ occidentales. En Europa existían también y precisamente el progreso. En las revoluciones surgieron en contra de esas tradiciones que acordaban que los reyes procedían de la divinidad, que los obispos tenían derechos sobre la ciudadanía, etc. Entonces lo que hace falta, insisto, es que muchos de los movimientos indigenistas lo que hacen son protestas 
contra no haber alcanzado una verdadera ciudadanía en el sentido positivo del término. Se les ha utilizado y mantenido marginados, sin higiene, sin cultura, sin darles las oportunidades positivas sino han recibido tratos terribles para quedarse con sus tierras y, claro, lógicamente ellos no se sienten vinculados a instituciones que tan poca cosa positiva les han aportado y les han traído horrores.

Lo primero que hay que ver es extender la ciudadanía como una forma en que todos deben participar, cada uno con un perfil propio y que siempre hablamos que no es lo mismo una democracia sueca que una en Italia, pero siempre los perfiles propios de los grupos humanos se mantiene, pero compartiendo unos temas comunes. A partir de allí, es donde ya los grupos humanos irán validando una serie de cosas que consideran importantes y las seguirán conservando y otros pues apartando un poco el recuerdo y la historia como en Europa.

B.A.: La democracia, sea esta liberal, republicana, comunitaria o deliberativa, requiere de bases éticas. Cuando usted se refiere a la ética, ¿a qué se refiere en realidad? ¿cuáles son sus desarrollos distintivos a diferencia de otros filósofos?

F.S.: Bueno, yo lo veo de la manera más sencilla del mundo. A mí me parece que yo llamo moral al conjunto de valores y de prácticas de experiencia que tiene una persona o una comunidad, aquellos valores y prácticas que son efectivamente considerados como propios por personas o comunidades. Y ética a la reflexión sobre esas cuestiones de valoración, la comparación entre unas valoraciones y otras, la memoria de valoraciones posibles, la fundamentación de estas valoraciones. O sea que moral es nuestros valores y ética es la reflexión de esos valores, la comparación con otros o con el pasado y el presente. Entonces yo tampoco he inventado nada, pero bueno lo que trato es de reflexionar y sobre todo despertar el interés en la reflexión de esos temas en los jóvenes. No darle a los jóvenes unas normas o dogmas de lo que deben pensar, sino decirles que sí hay algo que deben pensar, que es importante valorar, que no es importante vivir de un modo o de otro, que es importante buscar un arte de vivir y eso es lo que he intentado suscitar. Más que no tengo ninguna propuesta revolucionaria.

B.A.: Sin embargo a usted le caracteriza algo, no sólo abordar el tema para los jóvenes sino la ética de la esperanza en tiempos de desesperanza. 
F.S.: Yo no llamaría de desesperanza, yo la llamaría la ética está sobre la actividad y todo lo que es activo espera algo, si no, no actuaría. La actividad está ligada a creer que nos va a llevar a alguna parte el actuar incluso la persona al pegarse un tiro, también piensa que eso le va a aliviar algún tipo de sufrimiento. De modo que no es que yo sea esperanzado sino que la acción funciona a base de esperanzas sobre lo que se va o no se va a obtener. $Y$ como la ética es una reflexión sobre las acciones humanas, es inevitable en cierta medida estar esperanzado.

B.A.: Usted dice que introduce a los jóvenes en la reflexión sobre este tipo de temas. En una de sus obras afirma la importancia de trabajar en la autoestima de los jóvenes porque de lo contrario esto está sometido a la lógica del mercado. Este proceso de autoestima también es generalmente aceptado por las psicologías que emergen y refuerzan el libre mercado. ¿a que se refiere específicamente con reflexión y autoestima de los jóvenes?

F.S.: Yo creo que la autoestima o la conciencia de la propia dignidad humana es a la vez un objetivo y un punto de partida de la ética. Es decir, somos o nos planteamos problemas morales porque consideramos que la existencia humana está ligada a la de los otros seres humanos por algún tipo de vínculo no meramente accidental, no meramente zoológico sino por algo parecido a un proyecto o a una evaluación común. Entonces para que uno sienta que tiene que entrar al juego de la ética hace falta que se estime a sí mismo como digno y no sólo como un animal que se quiera alimentar y reproducir, sino como alguien que comparte valores y un símbolo de humanidad con otros. A eso yo lo llamo dignidad, autoestima, etc. Las personas que lo que trabajan es en revelar la impotencia o insignificancia de los seres humanos pues hacen una labor antiética.

B.A.: Finalmente, quisiera saber acerca de sus proyectos futuros.

F.S.: De momento no he vuelto a pensar nada, tengo muchas cosas pendientes, artículos y colaboraciones y cosas que he ido dejando aplazadas, ahora me dedicaré a eso y con el tiempo si surge alguna otra idea, pues ya me centraré en ella. 


\section{Reflexiones finales:}

La entrevista permite revisar distintas ideas y posiciones que en la actualidad se debaten en las ciencias sociales, incluyendo la pedagogía sobre las condiciones que se tienen para dar respuestas a las demandas de constitución de las identidades culturales, nacionales y el ejercicio de la ciudadanía plena en el marco de la era del conocimiento y la globalización. Uno de los problemas básicos que se plantea es la tensión que existe entre los procesos de homogenización que se promueven por nuestros sistemas educativos, que por una parte se reconfiguran en función de las transformaciones productivas en la era del conocimiento y la competitividad internacional y por otra parte, los requerimientos por parte de grupos, sectores y pueblos que demandan el reconocimiento a las diferencias étnicas, a la erradicación de la pobreza y al rescate del medio ambiente. En este sentido, los educadores deben de reflexionar y replantear críticamente las reformas a las prácticas educativas que no están exentas de las nuevas dinámicas locales, regionales y globales. 